\title{
Review
}

\section{Endometrial receptivity and PCOS; endometrial gene expression specificities - literature review}

\author{
Miro Šimun Alebić ${ }^{1, *}$ \\ ${ }^{1}$ Podobnik Maternity \& Gynecology Hospital, 10000 Zagreb, Croatia \\ *Correspondence: alebic11@gmail.com (Miro Šimun Alebić) \\ Academic Editor: Michael H. Dahan \\ Submitted: 26 November 2021 Revised: 3 January 2022 Accepted: 6 January 2022 Published: 12 February 2022
}

\begin{abstract}
Objectives: The purpose of this review is to provide an overview of existing studies on the specificities of gene expression in the endometrium in PCOS and possible molecular mechanisms linking those specificities with reproductive and obstetric consequences of PCOS. Mechanism: Polycystic ovary syndrome (PCOS) is a complex disorder combining features of reproductive, metabolic, and psychological disturbances. The effect of metabolic, inflammatory, and endocrine abnormalities on ovulatory function and oocyte quality has been seen as the main reproductive issue in PCOS women. However, even after the restoration of ovulation, this group exhibits lower than expected reproductive outcomes. Functionally relevant sequence alterations in genes involved in regulating endometrial receptivity could also be relevant in PCOS as a property independent of extra-endometrial influences. Findings: Hyperandrogenism, ovulatory dysfunction, and insulin resistance are associated with the alterations in endometrial gene expressions leading to suboptimal endometrial receptivity in PCOS. Endometrial steroid receptor malfunction seems to be a contibuting factor to the intrinsic suboptimal endometrial receptivity in PCOS. Conclusion: epigenetic or epigenomics mechanisms altering gene expressions on the endometrial level in PCOS should not be ruled out. Future studies should focus on investigating specificities of each PCOS phenotype and developing individual treatment strategies to meet the specific needs of every PCOS patient.
\end{abstract}

Keywords: Polycystic ovary syndrome; Endometrial receptivity; Endometrium; Implantation; Reproduction

\section{Introduction}

Polycystic ovary syndrome (PCOS) is a complex disorder combining features of reproductive, metabolic, and psychological disturbances. It is considered to be one of the most common conditions affecting $8-13 \%$ of reproductiveage women [1]. Patients with PCOS cope with a spectrum of diverse symptoms and signs comprising irregular menstrual cycles, hirsutism, infertility and pregnancy complications (early pregnancy loss, gestational hypertension, and preeclampsia/eclampsia) insulin resistance (IR), metabolic syndrome, prediabetes, type 2 diabetes (DM2) anxiety and depression compelling them to seek medical attention throughout their lifetime [2]. Studies focused on finding the link between genes and hormonal disturbances associated with predisposition for PCOS have identified over 200 candidate genes among which the majority is involved in encoding the androgen, LH, FSH, and leptin receptors [3]. In genetically predisposed individuals, environmental factors such as diet and unhealthy lifestyle are considered to be responsible for triggering the cascade of events leading to the development of PCOS-associated clinical and biochemical features [2].

It is well established that infertility, early pregnancy loss, gestational hypertension, and preeclampsia-eclampsia are more prevalent in women with PCOS [4-6]. Although anovulation is believed to be the main reason for reproductive and obstetric issues accompanying PCOS, even af- ter the anovulation was surpassed, pregnancy outcomes in these patients remained to be far from satisfactory [7-9]

Endometrial receptivity is a state of an endometrium defined by its readiness for embryo implantation [10]. It is acquired through the series of events governed by the action of ovary-derived steroid hormones on their endometrial receptors converting the endometrium from a tissue unique in its ability to reject the embryo implantation to a tissue that enhances implantation $[11,12]$. The final stages are attained under the dominant control of progesterone capable of shifting an estrogen-primed, proliferative endometrium into secretory and of controlling the cascade of growth factors and cytokines essential for proper communication on the maternal-embryonic interface [13,14]. However, the period in which endometrium provides an opportunity for an embryo to attach and implant, known as the window of implantation is time-limited and characterized by specific gene expression, morphologic and ultrastructural changes [15-17].

Endometrial receptivity failure can be defined as a state of suboptimal endometrial preparedness for implantation leading to a complete or partial rejection of the implantable embryo. Complete receptivity failure presents as infertility and/or (recurrent) early pregnancy loss. On the other end, even a modest receptivity failure can lead to partially abnormal embryo implantation could result in different obstetric complications such as gestational hypertension and preeclampsia-eclampsia [10]. 
In PCOS women, dysregulated expression of gene clusters due to aberrant ovarian hormonal and metabolic settings could lead to decreased endometrial receptivity. The purpose of this review is to provide an overview of existing studies on the specificities of gene expression in the endometrium in PCOS and possible molecular mechanisms linking those specificities with reproductive and obstetric consequences of PCOS.

\subsection{Endometrial receptivity}

Endometrial receptivity is a state of preparedness of endometrium for embryo implantation. It is a time-limited endometrial property induced by ovarian steroid hormones primarily by the action of progesterone after estrogen priming through the regulation of transcription of hundreds of genes [13,14,18-21]. Estrogen priming implies the promotion of mitotic activity of endometrial cells via estrogen receptors especially estrogen receptor alpha $(\mathrm{ER} \alpha)$ whose expression peaks in the late proliferative phase. The major form and the most potent natural estrogen 17beta-estradiol also induces progesterone receptor (PR) expression. Acting through its receptors postovulatory progesterone induces secretory changes and gradually muffles the endometrial response to ovarian steroid hormones including androgens that also have a significant impact on endometrial stromal cell proliferation, migration, and survival [22-24]. As a result, at the time of implantation in normally cyclic women, ER, PR and AR are selectively down-regulated in the epithelial compartment of the endometrium [23,25-27].

This dynamic and precisely controlled expression of endometrial steroid receptors is of utmost importance for the proper decidualization and optimal endometrial receptivity. It ensures epitheloid transformation of endometrial stromal cells into decidual cells during which they acquire intercellular junctions and become secretory active. In addition, epithelial cells go through changes in both, the plasma membrane and the cytoskeleton, resulting in the transformation of microvilli at the implantation site which is accompanied by simultaneous changes in cell adhesion receptors and ligands [14,18,28-30].

Such changes in endometrial gene expression bring up the cascade of growth factors and cytokines working as the prime paracrine mediators of the dialogue at the maternalembryonic interface [14]. Among numerous factors implicated to have a role in implantation, the interplay of PR, ER, leukemia inhibitory factor (LIF), insulin-like growth factor binding protein 1 (IGF-BP1), transforming growth factor beta $(\mathrm{TGF} \beta)$, tumor necrosis factor alfa (TNF $\alpha)$, interleukin 15 (IL-15) and leptin as well as cell adhesion molecules such as integrins and mucins, seem to be crucial in allowing anchorage and migration of cytotrophoblastic cells [31,32]. Thus, a receptive endometrium, together with the implantable embryo, represents a key requirement for synchronized dialog between maternal and embryonic tissues resulting in successful implantation [18,21,33,34].

\subsection{Endometrial receptivity in PCOS}

According to the ESHRE/ASRM 2003 definition, PCOS diagnosis in adults requires the presence of at least two of the following criteria - oligo/anovulation (OA), hyperandrogenism (HA) and polycystic ovarian morphology (PCOM), and the exclusion of other endocrinologic disorders presenting with similar clinical manifestations [35]. Although insulin resistance and overweight/obesity are not included in the criteria for PCOS diagnosis, their prevalence is found to be as high as $75 \%$ and $54 \%$, respectively [36]. The effect of metabolic, inflammatory, and endocrine abnormalities on ovulatory function and oocyte quality has been seen as the main reproductive issue in PCOS women. However, even after the restoration of ovulation, this group exhibits lower than expected reproductive outcomes, with a higher-than-expected rate of spontaneous miscarriage [24]. As endometrial receptivity is a hormonally dependent event, it is plausible that endocrinologic and metabolic disarrangements of PCOS could alter the endometrial gene expression and corrupt the process on the smaller or the bigger scale. Furthermore, functionally relevant sequence alterations in genes involved in regulating endometrial receptivity could also be relevant in PCOS as a property independent of extra-endometrial influences.

The endometrial receptivity array (ERA) test attempts to evaluate the gene expression profile to identify the specific transcriptomic signature of the implantation window. It was used clinically and claimed that it could be helpful in patients with repeated implantation failure. In PCOS patients, by using similar methods, screening on 21,571 genes showed down-regulation of several endometrialreceptivity-related genes like transmembrane 4 superfamily member 4 (TM4SF4) and matrix metalloproteinase 26 (MMP26) [37]. However, the clinical value and applicability of these findings are still a matter of debate [38].

\subsection{Overexpression of estrogen receptors and progesterone resistance}

Anovulation in PCOS is characterized by overexpression of $\operatorname{ER} \alpha$ and $\mathrm{AR}$ in endometrial cells. It has been shown that the molecular basis of this phenomenon is the absence of cyclic P4- induced down-regulation of these receptors resulting in a relatively low but constant and prolonged promotion of estrogen-dependent gene expression in endometrial cells [39]. Analysis of the p160 steroid receptor coactivator (SRC) family has revealed that in hyperandrogenic oligo/anovulatory PCOS patients throughout the menstrual cycle two coactivators of $\mathrm{ER} \alpha$ were upregulated in endometrial epithelial and stromal cells resulting in $\mathrm{ER} \alpha$ oversensitivity to estrogen action [40].

In oligo-anovulatory patients with PCOS, PR expression is also up-regulated predominantly in the epithelial rather than the stromal compartment. PR expression dysregulation and maldistribution as a consequence have the altered expression of numerous implantation-related P4- 
regulated genes negatively impacting the pseudodecidualisation of endometrial stromal cells in these patients [41]. It was supported by DNA microarray analysis studies demonstrating down-regulation of endometrial expression of claudin-4, mitogen-inducible gene 6 (MIG6), leukemia inhibitory factor (LIF), mucin-1, and many others in PCOS compared to non-PCOS women and animal models [37,4244].

The functional imperfection of PR was also offered as a plausible explanation for the suboptimal endometrial response to the P4 action in PCOS. The formation of the functional P4-PR complex is a necessity for the activation of the genes required for implantation and decidualization including homeobox transcription factors (e.g., HOXA-10), growth factors, and cytokines [45,46]. A competent PR consists of a receptor monomer, a $90-\mathrm{kDa}$ heat shock protein (Hsp90) dimer, the co-chaperone $\mathrm{p} 23$, and one of four co-chaperones containing a tetratricopeptide repeat (TPR) domain which include two members of FK506 binding family FKBP51 and FKBP52. Although they are structurally similar, FKBP51 and FKBP52 exert distinct functional properties. In vitro, FKBP52 amplifies the function of AR and PR, while FKBP51 works against PR functions $[42,47,48]$. In FKBP52 gene knock-out murine models compromised PR functions led to total failure of the uterus to support blastocyst implantation [48-50]. In squirrel monkeys, FKBP51 overexpression is linked to naturally occurring progestin resistance [47]. Dysregulated expression of Fkbp52 and Ncoa2 overlaps with the aberrant PGRtargeted gene expression in PCOS-like rats before and after implantation [51]. These animal models suggest possible mechanisms of PR resistance requiring further investigation in humans.

\subsection{Overexpression of androgen receptors}

$\mathrm{AR}$, a member of a nuclear receptor superfamily, is a ligand-dependent transcription factor. In normal cyclic women, ARs are predominantly distributed in the stromal compartment compared to the glandular compartment throughout the cycle, having higher concentrations in the estrogen-dominated, late proliferative stage compared to the P4-dominated, secretory phase $[27,52,53]$. Similar to $\mathrm{PR}$ receptors, they are maintained in a state of readiness for ligand-binding through interactions with several chaperones and co-chaperones [54]. In PCOS women, the overall AR expression is increased in both epithelial and stromal compartments. However, in the glandular compartment, endometrial AR are expressed significantly more during the proliferative and secretory phase, while in the stromal and luminal cells, the up-regulation is limited to the secretory phase only [27]. However, an excessive androgen receptor expression in endometrial cells was observed even in ovulatory women with PCOS, which is attributed to the downregulation of the Wilms tumor suppressor (WT1) gene expression during the window of implantation [55]. In hyper- androgenic PCOS it also can be attributed to the increased androgen level [27]. Moreover, potential dysregulation of FKBP51 could also have an impact on androgen-related endometrial gene expressions due to its known AR promotion activity [56].

The dysregulations of estrogen, progesterone, and androgen receptors are shown in Table 1.

Table 1. Summary of steroid receptor expression dysregulations in PCOS.

\begin{tabular}{lc}
\hline Receptor & Dysregulation \\
\hline estrogen receptor alfa & $\begin{array}{c}\text { overexpression } \\
\text { oversensitivity } \\
\text { overexpression } \\
\text { progesterone receptor } \\
\text { maldistribution } \\
\text { androgen receptor }\end{array}$ \\
\hline
\end{tabular}

\subsection{Dysregulation of expression of other endometrial receptivity-related molecules}

The expression of other molecules important for endometrial receptivity has also been reported as dysregulated in PCOS. Dickkhopf homolog 1 (DKK-1) was found to be overexpressed in PCOS theca cells resulting in increased inhibition of the Wnt signaling, which is an important pathway for cell specification and epithelial-mesenchymal interactions. Wnt-7a, a member of the Wnt family, is found to be crucial in the development of uterine glands in animal models, suggesting that this pathway may also disrupt the endometrial receptivity in PCOS [57]. The expression levels of angiogenic factors such as vascular endothelial growth factor (VEGF) and fibroblast growth factors (FGFs) were found to be altered in PCOS. Serum and follicular fluid concentrations of VEGF and bFGF in PCOS patients were found to be higher compared with controls [58]. VEGF concentrations in the uterine fluid of all pregnancy groups were significantly higher compared with the no pregnancy group $(p<0.05)$ [59]. Concentrations of bFGF in follicular fluid were considered as an FSH-dependent growth factor since its levels were inversely correlated with the percentage of mature oocytes collected [58,60]. Both are involved in neovascularization but also with estrogenindependent mitogenic effects.

In the mid-secretory phase of ovulatory cycles in oligoovulatory hyperandrogenic PCOS, up-regulated endometrial expressions of $\mathrm{ER} \alpha, \mathrm{AR}$ and PR alter the expression of endometrial receptivity-related molecules, specifically, $\alpha \mathrm{v} \beta 3$-integrin and HOXA-10 [41,61].

$\alpha \mathrm{v} \beta 3$-integrin is a member of a large integrin family of cell adhesion molecules. Integrins are the major class of receptors for the ECM and participate in cell-cell and cellsubstratum interaction [62]. The time of the $\alpha v \beta 3$-integrin 
appearance on the surface of the endometrial epithelium coincides with the opening of the implantation window and it seems that the selective down-regulation in PR expression in the secretory endometrial epithelium is initiation signal for the expression of this integrin $[63,64]$. The absence of $\alpha \mathrm{v} \beta 3$ - integrin and the persistence of the epithelial PR levels were found also in luteal phase deficiency, endometriosis, and unexplained infertility [64].

HOXA-10 is a member of a transcription factor family that is especially active during development and has been shown to be important for uterine function. In the anovulatory cycle, epithelial HOXA-10 expression is low during the proliferative phase and increased in the secretory phase, and expression throughout the menstrual cycle with the increased expression in the pseudodecidual cells [65]. Estrogen-progesterone-dependent manner of expression has been demonstrated in the mouse uterus and human endometrium correlating with the time of implantation in women [66,67]. Decreased expression of HOXA-10 was found in endometriosis, hydrosalpinges, and unexplained infertility correlating with the lower level of $\alpha \mathrm{v} \beta 3$ - integrin [65].

Altogether, these data corroborate in favor of similar molecular patterns of suboptimal endometrial receptivity in PCOS and other clinical entities.

\subsection{Obesity and insulin resistance-related endometrial changes}

In general, significantly lower live birth rates in lean RC-PCOS patients were observed when compared to age and BMI matched controls after single euploid blastocyst transfer in vitrified-warmed cycles indicating obesity independent PCOS-related impairment of implantation in these patients [68]. PCOS is often associated with insulin resistance, whether it is obesity-related and/or obesityindependent, both having the same consequence - compensatory hyperinsulinemia. The binding of insulin to target receptors results in activation of the PI3K/Akt signaling pathway which plays a key role in multiple cellular processes such as glucose metabolism, apoptosis, cell proliferation, transcription, and cell migration. In addition, it induces translocation of insulin-dependent glucose transporters (e.g., SLCA2A4) to the cell surface of endometrial epithelial cells which is the crucial step for cellular glucose uptake and one of the key points for nutritional support of early embryo implantation [69].

In the endometrial biopsy samples taken during implantation window from obese women with PCOS diagnosed by Rotterdam criteria (RC-PCOS), the overexpression and abnormal epithelial expression ER $\alpha, \mathrm{AR}$, and steroid receptor coactivators, as well as down-regulation of alpha(v)beta3 ( $\alpha \mathrm{v} \beta 3$ )-integrin, HOXA-10, and IGFBP1 , were observed $[27,35,70,71]$. Furthermore, in obese insulin-resistant patients with PCOS, SLCA2A4 mRNA is significantly downregulated and negatively correlated with homeostasis model assessment insulin resistance index (HOMA-IR), leading to the impairment of glucose uptake in endometrial tissue and endometrial differentiation [72-74].

When compared to BMI-matched non-PCOS controls, PCOS patients exhibit decreased levels of adiponectin. This is linked to a potentially detrimental effect on endometrial receptivity, as adiponectin molecule is also found to be engaged in proper endometrial decidualization and embryo implantation [31,71]. In accordance with these findings, insulin-resistant PCOS patients had significantly lower implantation, clinical pregnancy, and ongoing pregnancy rates after IVM-IVF cycles although embryo development was not found to be affected when age, BMI, and lipid profiles were controlled. These findings suggest a significant role of functional changes in the endometrium in preventing a successful pregnancy outcome in women with PCOS [75].

Key gene expression specificities of PCOS are shown in Table 2.

Table 2. Key gene expression specificities in PCOS.

\begin{tabular}{lccc}
\hline & type & phenotypes & cell types \\
\hline $\mathrm{ER} \alpha$ & overexpression & all & $\mathrm{E}+\mathrm{S}$ \\
$\mathrm{AR}$ & overexpression & $\mathrm{OA}$ & $\mathrm{E}+\mathrm{S}$ \\
p160 SRC & upregulation & $\mathrm{HA}+\mathrm{OA}$ & $\mathrm{E}+\mathrm{S}$ \\
$\mathrm{PR}$ & overexpression & all & $\mathrm{E}$ \\
$\mathrm{PR}$ & downregulation & all & $\mathrm{S}$ \\
P4 regulated genes & down & all & $\mathrm{S}$ \\
cell-proliferation genes & up & all & $\mathrm{E}+\mathrm{S}$ \\
\hline
\end{tabular}

ER $\alpha$, estrogen receptor alfa; AR, androgen receptor; p160 SRC, p160 steroid receptor coactivator; PR, progesterone receptor; $\mathrm{P} 4$, progesterone; OA, (oligo) anovulatory; HA, hyperandrogenic; E, epithelial; S, stromal.

\section{Endometrial effects of medications used for ovulation induction and ovarian stimulation}

\subsection{Antiestrogenic agents}

Letrozole (LTZ) is an aromatase inhibitor that transiently reduces E2 levels resulting in FSH secretion rise. When used for ovulation induction in PCOS patients, LTZ alters the endometrial gene expression without binding to ER, in contrast to clomiphene-citrate (CC). During induction of ovulation CC competitively binds to ER thus inhibiting estrogen-induced gene expression which is in charge of preovulatory endometrial proliferation. However, CC does not seem to affect the postovulatory endometrial ER overexpression and excessive endometrial susceptibility to the estrogen action observed in PCOS patients [40]. Compared to CC, LTZ induces more profound qualitative and quantitative changes in the expression of cytokines, namely LIF, 
Table 3. Endometrial effects of medications.

\begin{tabular}{llc}
\hline Medication & Effects & Study subjects \\
\hline antiestrogens & change in LIF, LIF - receptor, DKK-1, integrin $\alpha \mathrm{v} \beta 3$, VEGF, and FGF-22 concentration & human \\
metformin & increases GLUT4 expression & human \\
& reduces PR & animal \\
& increased both expression and secretion of IGFBP-1 and prolactin & animal \\
FSH & autophagy and apoptosis of endometrial cells & HEC \\
HCG/LH & up-regulation of pro-proliferative epiregulin gene & HEC \\
flutamide & increased expressions of prl8a2mRNA, cyclin D3 protein & animal \\
progestins & induce FKBP51 mRNA and protein expression & HEC \\
\hline
\end{tabular}

LIF, leukemia inhibitory factor; DKK-1, Dickkhopf homolog 1; VEGF, vascular endothelial growth factor; FGF-22, fibroblast growth factor-22; GLUT4, glucose transporter 4 protein; PR, progesterone receptor; IGFBP-1, insulin-like growth factor binding protein 1 ; HEC, human endometrial culture.

LIF - receptor, DKK-1, integrin $\alpha \mathrm{v} \beta 3$, VEGF, and FGF22 in uterine fluid and biopsy samples indicating better endometrial receptivity compared to CC [59,76,77]. Endometrial ultrasonic parameters [endometrial thickness (ET), endometrial volume (EV), vascularization index (VI), flow index (FI), vascularization flow index (VFI)], were found to be significantly higher after LTZ compared to CC induction as well as the clinical pregnancy and ongoing pregnancy rates [59].

This was the rationale behind the recommendation for LTZ to be the first-line therapy for the induction of ovulation in oligo/anovulatory PCOS [78]. The successful ovulation rate did not differ between the LE group and the CC group $(p>0.05)$.

\subsection{Metformin}

Metformin increases the expression of endometrial glucose transporter 4 protein (GLUT4) leading to the improvement of the endometrial IR in obese patients with PCOS [73]. On animal PCOS models and/or PCOS patients, it suppressed PR expression, corrected the abnormal expression of PR-targeted genes, and remarkably increased both expression and secretion of IGFBP-1 and prolactin in endometrial stromal cells following the estrogenprogesterone (EP) treatment thus hampering EP-induced decidualization by altering expression of multiple cytokines, MMP-2, MMP-9 and PGR via regulating p38 MAPK signaling pathway [51,79].

\subsection{Gonadotrophins}

Gonadotrophins are usually used in anovulatory PCOS as a second line of therapy for ovulation induction in case of first-line agent failure or if reduced chances of conception are observed by using first-line treatments (e.g., anti-estrogenic endometrial effects) and for in-vitro fertilization (IVF) in women with PCOS. They are also used for ovarian stimulation in cases who require IVF to improve their chances for pregnancy and live birth [78]. Transovarian actions apart, gonadotrophins also affected the en- dometrium directly by targeting their endometrial receptors, follicle-stimulating hormone receptor (FSHR), and luteinizing hormone and human chorionic gonadotrophin receptor (LHCGR). In collected endometrial samples, different gonadotrophins affected endometrial cell viability differently. The expression of cell-death-related genes was observed in the samples treated with FSH. In contrast, in the samples treated with HCG and LH, the up-regulation of the pro-proliferative epiregulin gene was observed. In addition, LH or HCG prevented FSH-induced autophagy and apoptosis in endometrial samples with combined treatment [80].

Morphological changes in the secretory endometrium, as well as changes in the biochemical profile of endometrial fluid and endometrial ER and PR expression, were observed in patients treated with gonadotrophins in ovarian stimulation cycles for IVF [81-85]. Although this issue remained controversial, it has been suggested that it could have a detrimental effect on endometrial receptivity and, consequently, on pregnancy and obstetric outcomes [86]. However, PCOS patients tend to have an excessive response to gonadotrophins during ovarian stimulation, higher estradiol levels, and increased risk of ovarian hyperstimulation syndrome (OHSS) compared to non-PCOS due to the large cohort of recruitable follicles [87]. Such high estradiol concentrations could have a detrimental effect on endometrial receptivity which could be improved by lowering excessively high estradiol concentrations and/or by using other OHSS preventive measures $[86,88,89]$.

Immature oocyte retrieval for in vitro maturation (IVM) is usually performed before the development of a dominant follicle shortening the follicular phase and preventing the increment of serum estradiol to the levels ensuring adequate endometrial proliferation [90]. To encounter this effect, exogenous estrogens are usually administered with an accompanying boost of endometrial steroid receptor expression. Even when high serum progesterone levels were achieved by progesterone supplementation, the downregulation of PR and ER expressions was not accomplished. 
This corroborates against optimal endometrial receptivity in fresh embryo transfers in IVM cycles [91].

\section{Endometrial effects of other medications}

\subsection{Antiandrogens}

Flutamide, a nonsteroidal antiandrogen, was found to ameliorate decidualization and endometrial angiogenesis in hyperandrogenic mice and by doing so it improved the poor endometrial receptivity. This was accounted to the increased expressions of prl8a2mRNA, cyclin D3 protein, and the increment in the number of uterine natural killer cells [92]. However, in humans, antiandrogens without the concomitant use of oral contraception cannot be recommended to avoid fetal male under-virilization in the event of pregnancy [78].

\subsection{Progestins}

Progestins, specifically medroksiprogesteron-acetate (MPA) and etonogestrel (ETO) are demonstrated to induce FKBP51 mRNA and protein expression in cultured human endometrial stromal cells. However, compared with MPA and ETO, micronized P4 may exert a milder PR-mediated transcriptional activity on the FKBP51 gene. However, none of the three above-mentioned progestins affected the expression of the FKBP52 gene [93].

Summary of endometrial effects of medications is presented in Table 3.

\section{Conclusions}

In general, anovulation is the primary event associated with infertility in PCOS patients with an obvious impact on the molecular behavior in the endometrium in PCOS. However, endometrial gene expression in the secretory endometrium/window of implantation is altered even after induction of ovulation or in spontaneous cycles potentially diminishing the endometrial capacity for implantation. The uterine fluid analysis seems to be a promising diagnostic tool for the identification of PCOS patients with alteration in the secretion of cytokines associated with endometrial receptivity. Several studies forebode metformin as the most promising candidate to reverse adverse endometrial gene expression. Animal studies demonstrated interesting effects of antiandrogens and progestins. However, nowadays, specific treatment strategies could not be recommended. PCOS is a complex and heterogeneous syndrome characterized by different combinations of hyperandrogenism, ovulatory dysfunction, and insulin resistance, which may have an impact on endometrial receptivity. There are also studies corroborating in favor of intrinsic suboptimal endometrial receptivity in PCOS attributed to endometrial steroid receptor malfunction. In this view, epigenetic or epigenomics mechanisms altering gene expressions on the endometrial level in PCOS should not be ruled out. Together with the clinical and metabolic heterogeneity of the PCOS, this im- poses that future studies on this subject should focus on investigating specificities of each PCOS phenotype and developing individual treatment strategies to meet the specific needs of every PCOS patient.

\section{Author contributions}

MŠA conceived and wrote the manuscript.

\section{Ethics approval and consent to participate}

Not applicable.

\section{Acknowledgment}

The author is grateful to Sanja Šale for her invaluable feedback on the manuscript.

\section{Funding}

This research received no external funding.

\section{Conflict of interest}

The author declares no conflict of interest.

\section{References}

[1] Teede HJ, Misso ML, Costello MF, Dokras A, Laven J, Moran $\mathrm{L}$, et al. Recommendations from the international evidencebased guideline for the assessment and management of polycystic ovary syndrome. Clinical Endocrinology. 2018; 89: 251268.

[2] Fauser BCJM, Tarlatzis BC, Rebar RW, Legro RS, Balen AH, Lobo R, et al. Consensus on women's health aspects of polycystic ovary syndrome (PCOS): the Amsterdam ESHRE/ASRMSponsored 3rd PCOS Consensus Workshop Group. Fertility and Sterility. 2012; 97: 28-38.e25.

[3] Ajmal N, Khan SZ, Shaikh R. Polycystic ovary syndrome (PCOS) and genetic predisposition: a review article. European Journal of Obstetrics \& Gynecology and Reproductive Biology: X. 2019; 3: 100060 .

[4] Kim JY, Song H, Kim H, Kang HJ, Jun JH, Hong SR, et al. Transcriptional profiling with a pathway-oriented analysis identifies dysregulated molecular phenotypes in the endometrium of patients with polycystic ovary syndrome. The Journal of Clinical Endocrinology \& Metabolism. 2009; 94: 1416-1426.

[5] Boomsma CM, Eijkemans MJC, Hughes EG, Visser GHA, Fauser BCJM, Macklon NS. A meta-analysis of pregnancy outcomes in women with polycystic ovary syndrome. Human Reproduction Update. 2006; 12: 673-683.

[6] Sha T, Wang X, Cheng W, Yan Y. A meta-analysis of pregnancyrelated outcomes and complications in women with polycystic ovary syndrome undergoing IVF. Reproductive BioMedicine Online. 2019; 39: 281-293.

[7] Melo A, Ferriani R, Navarro P. Treatment of infertility in women with polycystic ovary syndrome: approach to clinical practice. Clinics. 2015; 70: 765-769.

[8] Legro RS, Barnhart HX, Schlaff WD, Carr BR, Diamond MP, Carson SA, et al. Clomiphene, Metformin, or both for Infertility in the Polycystic Ovary Syndrome. New England Journal of Medicine. 2007; 356: 551-566.

[9] Legro RS, Brzyski RG, Diamond MP, Coutifaris C, Schlaff WD, Casson P, et al. Letrozole versus Clomiphene for Infertility in the Polycystic Ovary Syndrome. New England Journal of Medicine. 2014; 371: 119-129. 
[10] Lessey BA, Young SL. What exactly is endometrial receptivity? Fertility and Sterility. 2019; 111: 611-617.

[11] Wilcox AJ, Baird DD, Weinberg CR. Time of Implantation of the Conceptus and Loss of Pregnancy. New England Journal of Medicine. 1999; 340: 1796-1799.

[12] Rossman I. The deciduomal reaction in the rhesus monkey (Macaca mulatta). i. the epithelial proliferation. American Journal of Anatomy. 1940; 66: 277-365.

[13] Lessey BA. Assessment of endometrial receptivity. Fertility and Sterility. 2011; 96: 522-529.

[14] Rashid NA, Lalitkumar S, Lalitkumar PG, Gemzell-Danielsson $\mathrm{K}$. Endometrial receptivity and human embryo implantation. American Journal of Reproductive Immunology. 2011; 66: $23-$ 30.

[15] Noyes RW, Hertig AT, Rock J. Dating the endometrial biopsy. American Journal of Obstetrics and Gynecology. 1975; 122: 262-263.

[16] Navot D, Scott RT, Droesch K, Veeck LL, Liu H, Rosenwaks $Z$. The window of embryo transfer and the efficiency of human conception in vitro. Fertility and Sterility. 1991; 55: 114-118.

[17] Strowitzki T, Germeyer A, Popovici R, von Wolff M. The human endometrium as a fertility-determining factor. Human Reproduction Update. 2006; 12: 617-630.

[18] Sharkey AM, Macklon NS. The science of implantation emerges blinking into the light. Reproductive BioMedicine Online. 2013; 27: 453-460.

[19] Ruiz-Alonso M, Blesa D, Díaz-Gimeno P, Gómez E, FernándezSánchez M, Carranza F, et al. The endometrial receptivity array for diagnosis and personalized embryo transfer as a treatment for patients with repeated implantation failure. Fertility and Sterility. 2013 ; 100: 818-824.

[20] Haouzi D, Dechaud H, Assou S, De Vos J, Hamamah S. Insights into human endometrial receptivity from transcriptomic and proteomic data. Reproductive Biomedicine Online. 2012; 24: $23-$ 34.

[21] Paulson RJ. Hormonal induction of endometrial receptivity. Fertility and Sterility. 2011; 96: 530-535.

[22] Press MF, Udove JA, Greene GL. Progesterone receptor distribution in the human endometrium. Analysis using monoclonal antibodies to the human progesterone receptor. The American Journal of Pathology. 1988; 131: 112-124.

[23] Lessey BA, Killam AP, Metzger DA, Haney AF, Greene GL, McCarty KS. Immunohistochemical Analysis of Human Uterine Estrogen and Progesterone Receptors throughout the Menstrual Cycle* the Journal of Clinical Endocrinology \& Metabolism. 1988; 67: 334-340.

[24] Hosseinzadeh P, Barsky M, Gibbons WE, Blesson CS. Polycystic ovary syndrome and the forgotten uterus. F\&S Reviews. 2021; 2: 11-20.

[25] Garcia E, Bouchard P, De Brux J, Berdah J, Frydman R, Schaison $\mathrm{G}$, et al. Use of Immunocytochemistry of Progesterone and Estrogen Receptors for Endometrial Dating. the Journal of Clinical Endocrinology \& Metabolism. 1988; 67: 80-87.

[26] Lessey BA, Yeh I, Castelbaum AJ, Fritz MA, Ilesanmi AO, Korzeniowski $\mathrm{P}$, et al. Endometrial progesterone receptors and markers of uterine receptivity in the window of implantation. Fertility and Sterility. 1997; 65: 477-483.

[27] Apparao KBC, Lovely LP, Gui Y, Lininger RA, Lessey BA. Elevated Endometrial Androgen Receptor Expression in Women with Polycystic Ovarian Syndrome1. Biology of Reproduction. 2002; 66: 297-304

[28] Weimar CHE, Post Uiterweer ED, Teklenburg G, Heijnen CJ, Macklon NS. In-vitro model systems for the study of human embryo-endometrium interactions. Reproductive BioMedicine Online. 2013; 27: 461-476.

[29] Wewer UM, Faber M, Liotta LA, Albrechtsen R. Immunochem- ical and ultrastructural assessment of the nature of the pericellular basement membrane of human decidual cells. Laboratory Investigation. 1985; 53: 624-633.

[30] Katzenellenbogen BS. Dynamics of Steroid Hormone Receptor Action. Annual Review of Physiology. 1980; 42: 17-35.

[31] Dos Santos E, Serazin V, Morvan C, Torre A, Wainer R, de Mazancourt $\mathrm{P}$, et al. Adiponectin and leptin systems in human endometrium during window of implantation. Fertility and Sterility. 2012; 97: 771-778.e1.

[32] Cavagna M, Mantese JC. Biomarkers of endometrial receptivity-a review. Placenta. 2004; 24 Suppl B: S39S47.

[33] Cakmak H, Taylor HS. Implantation failure: molecular mechanisms and clinical treatment. Human Reproduction Update. 2011; 17: 242-253.

[34] Gonzalez RR, Devoto L, Campana A, Bischof P. Effects of leptin, interleukin- $1 \alpha$, interleukin- 6 , and transforming growth factor- $\beta$ on markers of trophoblast invasive phenotype. Endocrine. 2001 ; 15: 157-164.

[35] Fauser BCJM, Tarlatzis, Fauser, Chang, Aziz, Legro, et al. Revised 2003 consensus on diagnostic criteria and long-term health risks related to polycystic ovary syndrome. Human Reproduction. 2004; 19: 41-47.

[36] Tosi F, Bonora E, Moghetti P. Insulin resistance in a large cohort of women with polycystic ovary syndrome: a comparison between euglycaemic-hyperinsulinaemic clamp and surrogate indexes. Human Reproduction. 2017; 32: 2515-2521.

[37] Qiao J, Wang L, Li R, Zhang X. Microarray evaluation of endometrial receptivity in Chinese women with polycystic ovary syndrome. Reproductive BioMedicine Online. 2008; 17: 425435.

[38] Ben Rafael Z. Endometrial Receptivity Analysis (ERA) test: an unproven technology. Human Reproduction Open. 2021; 2021: hoab010.

[39] Giudice LC. Endometrium in PCOS: Implantation and predisposition to endocrine CA. Best Practice \& Research Clinical Endocrinology \& Metabolism. 2006; 20: 235-244.

[40] Gregory CW, Wilson EM, Apparao KBC, Lininger RA, Meyer WR, Kowalik A, et al. Steroid receptor coactivator expression throughout the menstrual cycle in normal and abnormal endometrium. the Journal of Clinical Endocrinology and Metabolism. 2002; 87: 2960-2966.

[41] Quezada S, Avellaira C, Johnson MC, Gabler F, Fuentes A, Vega M. Evaluation of steroid receptors, coregulators, and molecules associated with uterine receptivity in secretory endometria from untreated women with polycystic ovary syndrome. Fertility and Sterility. 2006; 85: 1017-1026.

[42] Savaris RF, Groll JM, Young SL, DeMayo FJ, Jeong J, Hamilton $\mathrm{AE}$, et al. Progesterone Resistance in PCOS Endometrium: a Microarray Analysis in Clomiphene Citrate-Treated and Artificial Menstrual Cycles. the Journal of Clinical Endocrinology \& Metabolism. 2011; 96: 1737-1746.

[43] Jeong J-, Lee HS, Lee KY, White LD, Broaddus RR, Zhang Y, et al. Mig- 6 modulates uterine steroid hormone responsiveness and exhibits altered expression in endometrial disease. Proceedings of the National Academy of Sciences. 2009; 106: 8677-8682.

[44] Margarit L, Taylor A, Roberts MH, Hopkins L, Davies C, Brenton AG, et al. MUC1 as a Discriminator between Endometrium from Fertile and Infertile Patients with PCOS and Endometriosis. the Journal of Clinical Endocrinology \& Metabolism. 2010; 95: 5320-5329.

[45] Dey SK, Lim H, Das SK, Reese J, Paria BC, Daikoku T, et al. Molecular Cues to Implantation. Endocrine Reviews. 2004; 25: 341-373.

[46] Lim H, Ma L, Ma W, Maas RL, Dey SK. Hoxa-10Regulates Uterine Stromal Cell Responsiveness to Progesterone during 
Implantation and Decidualization in the Mouse. Molecular Endocrinology. 1999; 13: 1005-1017.

[47] Hubler TR, Denny WB, Valentine DL, Cheung-Flynn J, Smith DF, Scammell JG. The FK506-Binding Immunophilin FKBP51 is Transcriptionally Regulated by Progestin and Attenuates Progestin Responsiveness. Endocrinology. 2003; 144: 2380-2387.

[48] Tranguch S, Cheung-Flynn J, Daikoku T, Prapapanich V, Cox $\mathrm{MB}, \mathrm{Xie} \mathrm{H}$, et al. Cochaperone immunophilin FKBP52 is critical to uterine receptivity for embryo implantation. Proceedings of the National Academy of Sciences of the United States of America. 2005; 102: 14326-14331.

[49] Tranguch S, Smith DF, Dey SK. Progesterone receptor requires a co-chaperone for signalling in uterine biology and implantation. Reproductive BioMedicine Online. 2006; 13: 651-660.

[50] Pratt WB, Toft DO. Steroid Receptor Interactions with Heat Shock Protein and Immunophilin Chaperones* Endocrine Reviews. 1997; 18: 306-360.

[51] Hu M, Zhang Y, Feng J, Xu X, Zhang J, Zhao W, et al. Uterine progesterone signaling is a target for metformin therapy in PCOS-like rats. Journal of Endocrinology. 2018; 237: 123-137.

[52] Mertens HJMM, Heineman MJ, Koudstaal J, Theunissen P, Evers JLH. Androgen receptor content in human endometrium. European Journal of Obstetrics \& Gynecology and Reproductive Biology. 1996; 70: 11-13.

[53] Fujimoto J, Nishigaki M, Hori M, Ichigo S, Itoh T, Tamaya T. The effect of estrogen and androgen on androgen receptors and mRNA levels in uterine leiomyoma, myometrium and endometrium of human subjects. the Journal of Steroid Biochemistry and Molecular Biology. 1994; 50: 137-143.

[54] Ketefian A, Jones MR, Krauss RM, Chen YI, Legro RS, Azziz $\mathrm{R}$, et al. Association study of androgen signaling pathway genes in polycystic ovary syndrome. Fertility and Sterility. 2016; 105: 467-473.e4.

[55] Gonzalez D, Thackeray H, Lewis PD, Mantani A, Brook N, Ahuja K, et al. Loss of WT1 Expression in the Endometrium of Infertile PCOS Patients: a Hyperandrogenic Effect? The Journal of Clinical Endocrinology \& Metabolism. 2012; 97: 957-966.

[56] Stechschulte LA, Sanchez ER. FKBP51 - a selective modulator of glucocorticoid and androgen sensitivity. Current Opinion in Pharmacology. 2011; 11: 332-337.

[57] Wood JR, Ho CKM, Nelson-Degrave VL, McAllister JM, Strauss JF. The molecular signature of polycystic ovary syndrome (PCOS) theca cells defined by gene expression profiling. Journal of Reproductive Immunology. 2004; 63: 51-60.

[58] Artini PG, Monti M, Matteucci C, Valentino V, Cristello F, Genazzani AR. Vascular endothelial growth factor and basic fibroblast growth factor in polycystic ovary syndrome during controlled ovarian hyperstimulation. Gynecological Endocrinology. 2006; 22: 465-470.

[59] Wang L, Lv S, Li F, Bai E, Yang X. Letrozole Versus Clomiphene Citrate and Natural Cycle: Endometrial Receptivity During Implantation Window in Women With Polycystic Ovary Syndrome. Frontiers in Endocrinology. 2021; 11: 532692.

[60] Fraser HM. Regulation of the ovarian follicular vasculature. Reproductive Biology and Endocrinology. 2006; 4: 18.

[61] Cermik D, Selam B, Taylor HS. Regulation of HOXA-10 expression by testosterone in vitro and in the endometrium of patients with polycystic ovary syndrome. the Journal of Clinical Endocrinology and Metabolism. 2003; 88: 238-243.

[62] Albelda SM, Buck CA. Integrins and other cell adhesion molecules. the FASEB Journal. 1990; 4: 2868-2880.

[63] Rai V, Hopkisson J, Kennedy S, Bergqvist A, Barlow DH, Mardon HJ. Integrins alpha 3 and alpha 6 are differentially expressed in endometrium and endometriosis. the Journal of Pathology. 1997; 180: 181-187.

[64] Lessey BA. Endometrial integrins and the establishment of uter- ine receptivity. Human Reproduction. 1998; 13: 247-258.

[65] Gui Y, Zhang J, Yuan L, Lessey BA. Regulation of HOXA-10 and its expression in normal and abnormal endometrium. MHR: Basic Science of Reproductive Medicine. 1999; 5: 866-873.

[66] Taylor HS, Arici A, Olive D, Igarashi P. HOXA10 is expressed in response to sex steroids at the time of implantation in the human endometrium. Journal of Clinical Investigation. 1998; 101: 1379-1384.

[67] Ma L, Benson GV, Lim H, Dey SK, Maas RL. Abdominal $\mathrm{B}(\mathrm{AbdB})$ HoxaGenes: Regulation in Adult Uterus by Estrogen and Progesterone and Repression in Müllerian Duct by the Synthetic Estrogen Diethylstilbestrol (DES) Developmental Biology. 1998; 197: 141-154.

[68] Luo L, Gu F, Jie H, Ding C, Zhao Q, Wang Q, et al. Early miscarriage rate in lean polycystic ovary syndrome women after euploid embryo transfer - a matched-pair study. Reproductive BioMedicine Online. 2017; 35: 576-582.

[69] Frolova AI, Moley KH. Glucose transporters in the uterus: an analysis of tissue distribution and proposed physiological roles. REPRODUCTION. 2011; 142: 211-220.

[70] Bellver J, Martínez-Conejero JA, Labarta E, Alamá P, Melo $\mathrm{MAB}$, Remohí J, et al. Endometrial gene expression in the window of implantation is altered in obese women especially in association with polycystic ovary syndrome. Fertility and Sterility. 2011; 95: 2335-2338.

[71] Schulte MMB, Tsai J, Moley KH. Obesity and PCOS. Reproductive Sciences. 2015; 22: 6-14.

[72] Czech MP, Corvera S. Signaling mechanisms that regulate glucose transport. the Journal of Biological Chemistry. 1999; 274: $1865-1868$.

[73] Zhai J, Liu C, Tian Z, Jiang Q, Sun Y. Effects of metformin on the expression of GLUT4 in endometrium of obese women with polycystic ovary syndrome. Biology of Reproduction. 2013; 87: 29.

[74] Fornes R, Ormazabal P, Rosas C, Gabler F, Vantman D, Romero $\mathrm{C}$, et al. Changes in the expression of insulin signaling pathway molecules in endometria from polycystic ovary syndrome women with or without hyperinsulinemia. Molecular Medicine. 2010; 16: 129-136.

[75] Chang EM, Han JE, Seok HH, Lee DR, Yoon TK, Lee WS. Insulin resistance does not affect early embryo development but lowers implantation rate in in vitro maturation-in vitro fertilization-embryo transfer cycle. Clinical Endocrinology. 2014; 79: 93-99.

[76] Wallace KL, Johnson V, Sopelak V, Hines R. Clomiphene citrate versus letrozole: molecular analysis of the endometrium in women with polycystic ovary syndrome. Fertility and Sterility. 2011; 96: 1051-1056.

[77] Roy K, Baruah J, Singla S, Sharma J, Singh N, Jain S, et al. A prospective randomized trial comparing the efficacy of Letrozole and Clomiphene citrate in induction of ovulation in polycystic ovarian syndrome. Journal of Human Reproductive Sciences. 2012; 5: 20.

[78] Teede H, Misso M, Costello M, Dokras A, Laven J, Moran L, et al. International evidence-based guideline for the assessment and management of polycystic ovary syndrome 2018. National Health and Medical Research Council. 2018; 1-198.

[79] Xiong F, Xiao J, Bai Y, Zhang Y, Li Q, Lishuang X. Metformin inhibits estradiol and progesterone-induced decidualization of endometrial stromal cells by regulating expression of progesterone receptor, cytokines and matrix metalloproteinases. Biomedicine \&Amp; Pharmacotherapy = Biomedecine \&Amp; Pharmacotherapie. 2019; 109: 1578-1585.

[80] Sacchi S, Sena P, Addabbo C, Cuttone E, La Marca A. Gonadotrophins modulate cell death-related genes expression in human endometrium. Hormone Molecular Biology and Clinical 
Investigation. 2020; 41.

[81] Garcia JE, Acosta AA, Hsiu JG, Jones HW. Advanced endometrial maturation after ovulation induction with human menopausal gonadotropin/human chorionic gonadotropin for in vitro fertilization. Fertility and Sterility. 1984; 41: 31-35.

[82] Kolb BA, Najmabadi S, Paulson RJ. Ultrastructural characteristics of the luteal phase endometrium in patients undergoing controlled ovarian hyperstimulation. Fertility and Sterility. 1997; 67: 625-630.

[83] Simon C, Cano F, Valbuena D, Remohi J, Pellicer A. Implantation: Clinical evidence for a detrimental effect on uterine receptivity of high serum oestradiol concentrations in high and normal responder patients. Human Reproduction. 1995; 10: 2432-2437.

[84] Noci I, Borri P, Coccia ME, Criscuoli L, Scarselli G, Messeri $\mathrm{G}$, et al. Hormonal patterns, steroid receptors and morphological pictures of endometrium in hyperstimulated IVF cycles. European Journal of Obstetrics \& Gynecology and Reproductive Biology. 1997; 75: 215-220.

[85] Develioglu OH, Hsiu JG, Nikas G, Toner JP, Oehninger S, Jones HW. Endometrial estrogen and progesterone receptor and pinopode expression in stimulated cycles of oocyte donors. Fertility and Sterility. 1999; 71: 1040-1047.

[86] Valbuena D, Jasper M, Remohí J, Pellicer A, Simón C. Ovarian stimulation and endometrial receptivity. Human Reproduction. 2000; 14 Suppl 2: 107-111.

[87] Esinler I, Bayar U, Bozdag G, Yarali H. Outcome of intracytoplasmic sperm injection in patients with polycystic ovary syndrome or isolated polycystic ovaries. Fertility and Sterility.
2005; 84: 932-937.

[88] Simón C, Garcia Velasco JJ, Valbuena D, Peinado JA, Moreno $\mathrm{C}$, Remohí $\mathrm{J}$, et al. Increasing uterine receptivity by decreasing estradiol levels during the preimplantation period in high responders with the use of a follicle-stimulating hormone step-down regimen. Fertility and Sterility. 1998; 70: 234-239.

[89] Devroey P, Polyzos NP, Blockeel C. An OHSS-Free Clinic by segmentation of IVF treatment. Human Reproduction. 2011; 26: 2593-2597.

[90] Requena A, Neuspiller F, Cobo AC, Aragonés M, GarcíaVelasco JA, Remohí J, et al. Endocrinological and ultrasonographic variations after immature oocyte retrieval in a natural cycle. Human Reproduction. 2001; 16: 1833-1837.

[91] Ortega-Hrepich C, Drakopoulos P, Bourgain C, Van Vaerenbergh I, Guzman L, Tournaye H, et al. Aberrant endometrial steroid receptor expression in in-vitro maturation cycles despite hormonal luteal support: a pilot study. Reproductive Biology. 2019; 19: 210-217.

[92] Gong H, Wu W, Xu J, Yu D, Qiao B, Liu H, et al. Flutamide ameliorates uterine decidualization and angiogenesis in the mouse hyperandrogenemia model during mid-pregnancy. PLoS ONE. 2019; 14.

[93] Kayisli OG, Kayisli UA, Basar M, Semerci N, Schatz F, Lockwood CJ. Progestins Upregulate FKBP51 Expression in Human Endometrial Stromal Cells to Induce Functional Progesterone and Glucocorticoid Withdrawal: Implications for Contraceptive- Associated Abnormal Uterine Bleeding. PLoS ONE. 2015; 10. 